\title{
Quality and Storability of Mango During Zero Energy Cool Chamber (ZECC)
}

\author{
Andi Dirpan ${ }^{1 *}$, Muhammad Tahir Sapsal ${ }^{1}$, Adiansyah Syarifuddin', Mulyati M \\ Tahir ${ }^{1}$, Kamilia Nur Yaumil Ali ${ }^{1}$, Abdul Kadir Muhammad² \\ ${ }^{1}$ Department of Agricultural Technology, Hasanuddin University, Makassar, Indonesia. \\ ${ }^{2}$ Center for Mechatronics and Control System, Mechanical Engineering Department, State Polytechnic \\ of Ujung Pandang, Indonesia. \\ *Corresponding author E-mail: dirpan@unhas.ac.id
}

\author{
How to Cite: Dirpan, A., Sapsal, M.T., Syarifuddin, A., Tahir. M., Ali, K.N.Y., Muhammad, \\ A.K. (2018). Quality and Storability of Mango During Zero Energy Cool Chamber (ZECC). \\ Int. J. Agr. Syst. 6(2): 119-129
}

\begin{abstract}
Many research have found that the use of zero energy cool chamber (ZECC) extend the shelf life of stored fruits and vegetables. There is a lack of study conducted in Indonesia about the use of ZECC to keep mangos after harvesting though. The present study, therefore, was aimed to understand the quality and storability of stored mangos in ZECC. Three different storage containers, a ZECC, ambient, and refrigerator with different average $R H$ and temperature, were used to place selected ripe mangos (Mangifera indica $L$ ) that were manually harvested from farmers' field nearby. The ZECC was set up at the residential complex for lecturer of Hasanuddin University as the experiment site. Results showed that mangos inside ZECC were acceptable until eleven days of storage after considering both quality and sensory evaluation. The result suggests that ZECC can maintain mango's quality and extend its shelf life, which reveals that ZECC seems promising for commercial application.
\end{abstract}

Copyright $\odot 2018$ IJAS. All rights reserved.

\section{Keywords:}

Mango; quality; storability; ZECC; postharvest technology

\section{Introduction}

Mango (Mangifera indica L) is known as one of the most popular tropical fruit in the world, that are cultivated in tropical and subtropical regions. Every year mangos production are increasing to address consumer demand (Jahurul et al., 2015; Marques, De Freitas, Pimentel, \& Pasquini, 2016; Schmilovitch, Mizrach, Hoffman, Egozi, \& Fuchs, 2000). However, after harvesting treatment of mangos in developing countries, i.e. Indonesia face a problem, in which there is a lack of storage caused by limited refrigerator and electricity in the most agricultural area. It was even reported that many farmers had limited financial capability to generate an expensive cooling system (Md. Parvez Islam \& Morimoto, 2015). An alternative to address this problem implies that the zero energy cool chamber (ZECC) is implementable as in its application electricity is not required, eco-friendly and low cost(M. P. Islam, Morimoto, \& Hatou, 2012, 2013; Md. Parvez Islam \& Morimoto, 2014; Singh, Singh, Joshi, Bagle, \& More, 
2010; Vala, Saiyed, \& Joshi, 2014). ZECC can be defined as a simple structure cooling system for vegetables and fruits storage consists of outer and inner brick walls with a filler material in between, half-ground storage space as well as a water supply system which require no electric energy(M. P. Islam et al., 2013; Md. Parvez Islam \& Morimoto, 2015; Md Parvez Islam \& Morimoto, 2012)

According to some ZECC studies, ZECC is an effective method for extending fruit and vegetable shelf life. In a study performed by Ganesan et al. (Ganesan, Balasubramanian, \& Bhavani, 2004), the ZECC method was applied to eggplants. The eggplants were stored in ZECC and at room temperature, resulted that with the addition of 1001 of water per day in ZECC method the shelf life enhancement reached up to 9 days. Other studies focusing on ZECC in banana(Narayana, Mustafa, \& Sathiamoorthy, 2002), lemon(Prabha, H.R, A.K, \& Ranjana, 2006), aonla fruit(Dhumal \& Karale, 2008; Singh et al., 2010), tomato(M. P. Islam et al., 2012, 2013; Md Parvez Islam \& Morimoto, 2012), grapes(Murugan, Ranjith, \& Vidhya, 2011), potato(Rayaguru, Khan, \& Sahoo, 2010) and apples(Sharma et al., 2010)supported that ZECC is recommended to the shelf life extension of mentioned fruits and vegetables.

Our earlier reports suggest that a combined application of ZECC and watering 20 liters per day decreases temperature and increases relative humidity inside ZECC that has potential in maintaining the quality of fruits and vegetables(Dirpan, Sapsal, Muhammad, Tahir, \& Rahimuddin, 2017). However, the research of how the quality and storability of fruits and vegetables stored in the ZECC has not been conducted yet. This study therefore aimed to understand the quality and storability of stored mangoes in ZECC.

\section{Materials and Method}

\subsection{Materials}

This research was performed at Food Processing Laboratory, Department Agricultural Technology, Hasanuddin University from March to November 2017. To achieve the research objectives, a ZECC was set up at the residential complex for lecturer of Hasanuddin University. The fruit used for the experiment was ripe mango (Mangifera indica L) collected from nearby farmers' field. Harvesting was done manually. Sending the product to the experiment site was done immediately after harvesting using plastic container. We washed the fruits with tap water to remove field heat soon after sorting for uniform size and undamaged product. One hundred mango fruits with free from fungal infection were selected, labeled and weighed. Finally, all fruits were stored into three different places which are ZECC (average $\mathrm{RH}=87.2 \%$, temperature $=26.2^{\circ} \mathrm{C}$ ), ambient (average $\mathrm{RH}=72.9 \%$, temperature $=28^{\circ} \mathrm{C}$ ) and refrigerator (average $\mathrm{RH}=50.9 \%$, temperature $=20.0^{\circ} \mathrm{C}$ ).

\subsection{Structure of the ZECC}

The design was based on our earlier ZECC construction(Dirpan et al., 2017). The ZECC's surface can be seen in Figure 1. 




Figure 1. ZECC was placed on the surface

\subsection{Storage Container}

Three perforated crates is made from fine grade high-density polyethylene capable of handling various types of fruits were used to store mango. Mangos were placed inside the perforated plastic crates and stored inside ZECC, ambient condition and refrigerator for qualitative evaluation.

\subsection{Quality Evaluation}

\subsection{1 pH}

We measured the $\mathrm{pH}$ using a portable digital $\mathrm{pH}$ meter (Oakton $\mathrm{pH} 510$, Singapore) through the direct immersion of the electrode in the fruit juice and three replicates of $\mathrm{pH}$ samples were taken daily until decay.

\subsubsection{Total soluble solids (TSS)}

We used a digital refractometer (Hanna HI 96804, India) to measure TSS with a measurement accuracy of Brix $\pm 0.1 \%$, and three replicates of TSS samples were taken daily until decay.

\subsubsection{Vitamin C}

To measure the vitamin C, we applied AOAC's official titrimetric method(Hernandez, Lobo, \& Gonzalez, 2006). In which, $2 \mathrm{ml}$ of the 3\% MPA and $8 \%$ acetic acid extracts were titrated with indophenol solution $\left(25 \% \mathrm{DCIP}\right.$ and $21 \% \mathrm{NaHCO}_{3}$ in demineralized water) until light, but distinct rose pink color appears and persists for more than 5 seconds. The indophenol solution was standardized daily with AA solution. Three replicates of vitamin $C$ were taken per day until decay.

\subsubsection{Total titratable acidity}

AOAC titration method with $0.1 \mathrm{M} \mathrm{NaOH}$ titration was applied to measure titratable acidity content (AOAC, 2005). Three replicates of total acids were taken per day until decay.

\subsubsection{Sensory evaluation}

Ten chosen and trained panelist was exploited to test the sensory quality of the mangos. The panelists were asked to evaluate the skin color, taste, aroma and texture 
of the mangos using a five-point hedonic scale with $1=$ very poor; $2=$ poor (limit of acceptable); 3 = good; $4=$ very good; 5 = excellent.

\subsubsection{Physiological loss in weight (PLW)}

The stored mangoes were evaluated daily by using an electric balance with the accuration of $0.1 \mathrm{~g}$ until decayed. Then, we recorded the physiological loss in weight (PLW) of stored mango periodically. The readings were made at one-day intervals during the experiment period. We then measured PLW by using the following formula:

Physiological loss in weight, $\%=\frac{(x 1-x)}{x} \times 100$

where,

$\mathrm{X} 1$ = Initial weight $(\mathrm{g})$

$\mathrm{X}=$ Weight $(\mathrm{g})$ at the end of storage time

\subsubsection{Measurement of moisture content}

We measured the moisture content using the oven drying method $\left(100{ }^{\circ} \mathrm{C}\right.$ for $\left.24 \mathrm{~h}\right)$. We used $10 \mathrm{~g}$ of fruit pulp samples for measurement. Weighing process of all samples was done by using an electric balance with an accuracy of $0.001 \mathrm{~g}$. We presented the wet basis moisture content as a percentage.

\subsection{Statistical analysis}

One-way analysis of variance (ANOVA) applied to analyze the total titratable acidity, Vitamin C and total soluble solids (TSS), while the significant differences among means were determined using Tukey's test with a level of significance of $\mathrm{P}<0.05$. SPSS software for Windows version 16.0 (SPSS Inc., IL, USA) and Microsoft Excel 2010 was used to analyze the data.

\section{Results and Discussion}

\subsection{Total titratable acidity, Vitamin C and total soluble solids (TSS)}

The chemical constituents of the mango fruit obtained at three conditions are reported in Table 1. The total titratable acidity of mangos decreased during ripening in three different storages, ZECC, ambient condition and refrigerator but the faster decline was observed when mangos were stored under ambient temperature. The relative higher ambient temperature led to higher rate of reduction in the total titratable acidity. Similar observations were reported by Baloch (2011) and (Baloch, Bibi, \& Jilani, 2013). It is known that ZECC reduces respiratory activity, thereby delaying the ripening process and consequently extending fruits shelf life through maintaining higher relative humidity and lower temperature during storage compared to the ambient air conditions (Dirpan et al., 2017; M. P. Islam et al., 2012; Md Parvez Islam \& Morimoto, 2012). In general, the ripening rate of mangos fruits as indicated by the rise in reducing sugar and fall in acidity was found to be much slower in ZECC when compared with storage at ambient condition. 
Table 1. Average values of chemical constituents measured at ripened stage for mango fruit, stored at different condition

\begin{tabular}{|c|c|c|c|c|c|c|c|c|c|c|c|c|c|}
\hline \multirow{2}{*}{ Parameters } & \multirow{2}{*}{ Treatments } & \multicolumn{11}{|c|}{ Storage (Days) } & \multirow[b]{2}{*}{11} \\
\hline & & 0 & 1 & 2 & 3 & 4 & 5 & 6 & 7 & 8 & 9 & 10 & \\
\hline \multirow{3}{*}{$\begin{array}{c}\text { Total } \\
\text { titratable } \\
\text { acidity }(\%)\end{array}$} & ZECC & 0.412 & $0.361^{b}$ & $0.245^{b}$ & $0.278^{a}$ & $0.214^{b}$ & $0.163^{b}$ & $0.133^{\mathrm{ab}}$ & $0.129 \mathrm{~b}$ & 0.129 & 0.116 & 0.115 & 0.113 \\
\hline & Ambient & 0.414 & $0.238^{\mathrm{a}}$ & $0.215^{\mathrm{a}}$ & $0.188^{c}$ & $0.136^{a}$ & $0.131^{\mathrm{a}}$ & $0.115^{a}$ & $0.119 a$ & - & - & - & - \\
\hline & Refrigerator & 0.418 & $0.337 \mathrm{c}$ & $0.275^{c}$ & $0.243^{b}$ & $0.237 \mathrm{c}$ & $0.229 c$ & $0.216^{\mathrm{b}}$ & $0.160^{c}$ & 0.127 & 0.118 & $0.11^{\mathrm{a}}$ & 0.112 \\
\hline \multirow{3}{*}{$\begin{array}{l}\text { Vitamin C } \\
(\mathrm{mg} / 100 \mathrm{~g})\end{array}$} & ZECC & 33.56 & 64.02 & $74.77^{b}$ & 61.81 & $69.29^{a}$ & $78.97 \mathrm{~b}$ & $71.95^{b}$ & $68.75^{b}$ & $50.38^{\mathrm{b}}$ & 40.43 & 30.54 & 24.98 \\
\hline & Ambient & 33.54 & 58.20 & $58.43^{\mathrm{ab}}$ & 54.72 & $58.20^{\mathrm{ab}}$ & $55.34^{\mathrm{ab}}$ & $46.01^{\mathrm{a}}$ & $59.09 \mathrm{ab}$ & - & - & - & - \\
\hline & Refrigerator & 33.43 & 45.30 & $39.94^{\mathrm{a}}$ & 39.18 & $44.95^{a}$ & $40.26^{a}$ & $55.76^{a b}$ & $50.77^{a}$ & $40.32^{\mathrm{a}}$ & 39.34 & 29.97 & 23.48 \\
\hline \multirow{3}{*}{$\begin{array}{l}\text { Total soluble } \\
\text { solids ( }{ }^{\circ} \text { Brix) }\end{array}$} & ZECC & 11.9 & $16.1^{\mathrm{b}}$ & $16.7^{\mathrm{b}}$ & $16.1^{\mathrm{c}}$ & $18.7^{c}$ & $13.2^{\mathrm{a}}$ & $12.0^{\mathrm{a}}$ & $13.5^{\mathrm{a}}$ & $11.6^{\mathrm{a}}$ & 13.7 & $11.1^{\mathrm{a}}$ & $14.2^{\mathrm{a}}$ \\
\hline & Ambient & 11.0 & $13.6^{\mathrm{a}}$ & $14.1^{\mathrm{a}}$ & $12.1^{a}$ & $14.6^{a}$ & $14.3^{\mathrm{b}}$ & $13.7 \mathrm{~b}$ & $13.8^{\mathrm{a}}$ & - & - & - & - \\
\hline & Refrigerator & 11.3 & $13.7 \mathrm{a}$ & $14.3^{\mathrm{a}}$ & $14.6^{\mathrm{b}}$ & $17.1^{\mathrm{b}}$ & $16.9^{c}$ & $13.6^{a}$ & $15.5^{\mathrm{b}}$ & $12.8^{\mathrm{b}}$ & 13.7 & $12.6^{\mathrm{b}}$ & $15.7^{b}$ \\
\hline
\end{tabular}

All measurements were performed in triplicate $(n=3)$. All data are expressed as the mean. Means of all parameters followed by different letters are significantly different, as determined by the Tukey test at $\mathrm{P}<0.05$.

The range of vitamin $C$ content in this study was 23.48 to $78.97 \mathrm{mg} / 100 \mathrm{~g}$ as can be seen in Table 1. The concentration of vitamin $C$ at control day was 33.43 to $33.56 \mathrm{mg} / 100 \mathrm{~g}$ almost similar to the previous study (Khader, 1990). There was no significant difference $(\mathrm{P}<0.05)$ in vitamin $\mathrm{C}$ content of mangos fruits observed from the interaction treatments at the time of harvest until the first day of storage. Highest value of vitamin C or ascorbic acid $(78.97 \mathrm{mg} / 100 \mathrm{~g})$ was found in ZECC treatment at the fifth day of storage, while the lowest value $(23.48 \mathrm{mg} / 100 \mathrm{~g})$ was recorded in ZECC treatment fruits at the eleventh and third day storage. In general, vitamin $C$ content of mangos were found at ZECC condition significantly higher compared to the ambient and refrigerator conditions (Table 1). This could be because low temperature and high relative humidity retards aging through reduced respiration rate and other undesirable metabolic changes. Zero energy cool chambers along with packaging materials, ventilation and anti-fungal treatments can help in minimizing the ascorbic acid losses in the stored fruits to some extent compared to the storage under ambient conditions(Lal Basediya, Samuel, \& Beera, 2013; Prabha et al., 2006; Sharma et al., 2010).

The total soluble solid content (TSS) of mangos treated with ZECC, ambient and refrigerator was found to range between 11.0 and $18.7^{\circ}$ Brix (Table 1 ). These values are in agreement with the findings of Hoa et.al (2002) who reported that TSS values of 9.0 to $17.5^{\circ}$ Brix for three varieties of mangos(Hoa, Ducamp, Lebrun, \& Baldwin, 2002). The general trend observed during the storage for total solids content of mango was an initial increase followed by a decrease (Table 1). This increase is caused by the degradation of starch in the mango into the simple sugar that increases sugar content of fruit during storage. This is consistent with the statement of Pandarinathan et al., (2010) that increase the sugar content in fruit during the ripening process is correlated with the total value of the SSC. Furthermore, the TSS increased with the advancement of maturity. The values for total soluble solid varied between 11.9 and 18.7 when stored at ZECC, from 11.0 to 14.6 when stored at ambient temperature and from 11.3 to 
17.1 during the storage using refrigerator. It is well known that, simple sugars and acids are the respiration substrates. The longer time of fruit respiration the higher rates of sugars and acids consumption (Tefera, Seyoum, \& Woldetsadik, 2008). This may explain the decrease in total soluble solid content in the fruit due to the prolong time of storage.

\subsection{Physiological loss in weight (PLW) and moisture content}

Figure 2(a) displays daily changes in PLW of mangos stored inside ZECC, ambient temperature and refrigerator. In this research, significant differences were found in PLW (in percent) of mangos stored in the ZECC and at ambient temperature (average of $28^{\circ} \mathrm{C}$ ) where the PLW of mangos inside the ZECC were lower than those stored other two applied conditions. The highest weight loss $(20.3 \%)$ was recorded from mangos stored at ambient temperature on day 8 followed by mangos stored in refrigerator and ZECC on day 11 with PLW $13.0 \%$ and $6.2 \%$ respectively. To investigate the difference in PLW among the treatments, the relationship between moisture content and PLW was examined. As shown in Figure $2(\mathrm{a})$ and (b), while the trend of mango stored in PLW at ambient temperature is high compared to those stored in refrigerator and ZECC, the trend of moisture content stored in PLW is lowest and it is followed by refrigerator and ZECC. This result found in this research was in agreement with a study done by Chien et al. (Chien, Sheu, \& Yang, 2007), in which the moisture content of mango cv. Irwin was investigated; the mango with the higher moisture had lower in PLW and vice versa. These results indicated that the quality of fruits and vegetables was affected by water loss during the storage, which depends on the temperature and relative humidity conditions(Baldwin et al., 1999). Talcott et al.(Talcott, Moore, Lounds-Singleton, \& Percival, 2005) mentioned that in maintaining the quality of most fruits and vegetables the storage under high $\mathrm{RH}$ and low temperature is considered as the most efficient method due to its effects on reducing respiration rate, transpiration, ethylene production, ripening, senescence, and rot development



(a)

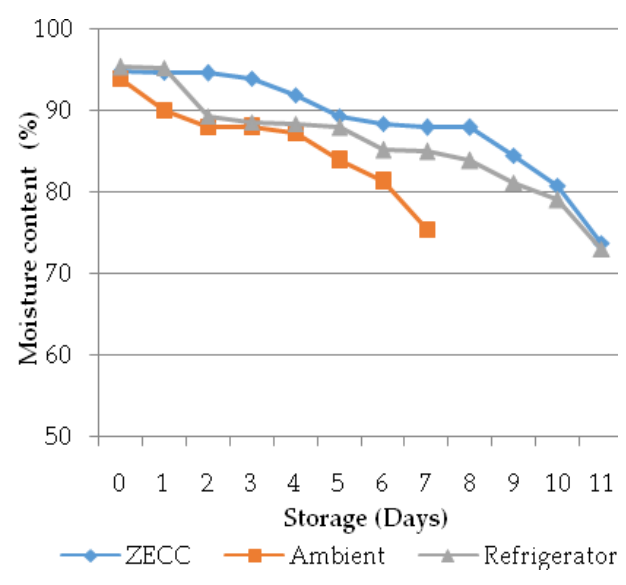

(b)

Figure 2. (a) Physiological loss in weight (PLW) of mangos during storage; (b) content of mangos during storage. 


\subsection{Sensory evaluation}

Figure 3(a) shows the taste of mangos in three different storage conditions. It can be clearly seen that in general there was an increasing trend first and followed by significant decrease. For instance the taste of mangos inside ZECC changes from 2.50 to 3.75 in four days of storage and gradually decreased to 2.80 after 11 days of storage. We suspect that this could be occurred due to acids, $\mathrm{pH}$ and sugar/acid ratio fluctuations(Malundo, Baldwin, Moshonas, Baker, \& Shewfelt, 1997). For flavor, it was observed from the result that the trend was almost similar with the taste. For example mangos flavor in ambient storage increased from 2.60 to 3.73 after fourth days of storage and gradually decreased to 2.80 after 8 days of storage (Figure. 3b). It could be explained by slower biochemical changes and no conversion of organic compounds into esters, aldehydes, acids, alcohols and ketones take place that contributed significantly to flavor of the mangos(No, Meyers, Prinyawiwatkul, \& Xu, 2007). While, in ambient temperature, decline in flavor score was started after 4 days of storage, and after that the fruits started spoiling. The reason for this might be due to the higher temperature in ambient atmosphere, particularly in daylight. Doreyappa \& Huddar (2001) reported that flavor of mangos after ripening showed significantly decreasing trend as the storage period proceeded when stored at 32 to $35^{\circ} \mathrm{C}$ (Doreyappa Gowda \& Huddar, 2001). It might be caused by fluctuations in acids, $\mathrm{pH}$ and sugar/acid ratio(Jitareerat, Paumchai, Kanlayanarat, \& Sangchote, 2007; Malundo et al., 1997)

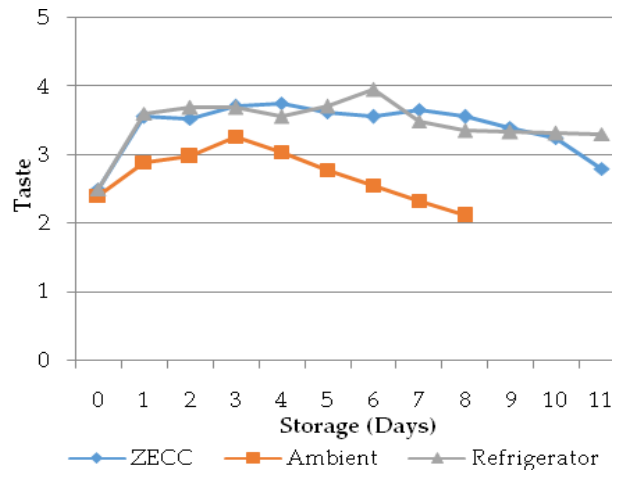

(a)



(c)

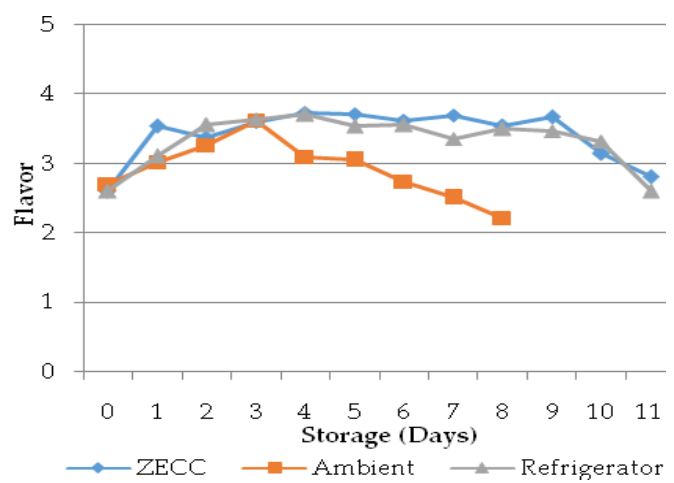

(b)

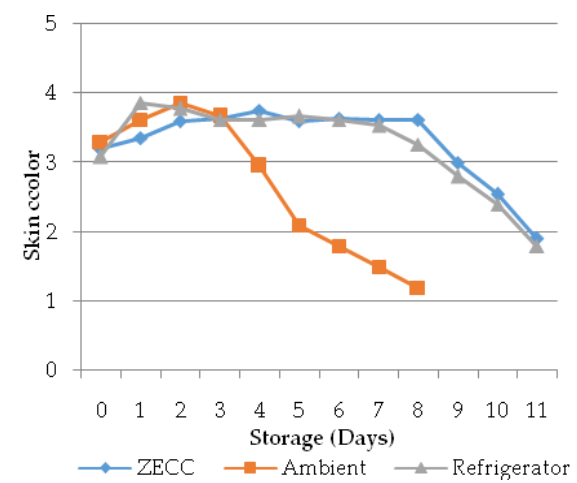

(d)

Figure 3. (a) Physiological loss in weight (PLW) of mangos during storage; (b) Moisture content of mangos during storage; (c) Texture score of mangos during storage; (d) Skin colour score of mangos during storage. 
In general, figure 3(c) shows the texture of mangos inside ZECC and refrigerator increased at the beginning of storage and then decreased slightly at the end of the storage. On the other hand, texture in ambient increased then decreased significantly. This trend can be explained in the way that the ripening of mango fruits is characterized by loss of firmness due to cell wall digestion by pectin-esterase, polygalacturonase and other enzymes, and this process is increased by the increase in storage temperature (Baloch et al., 2013). One of the famous quality parameter of mango is skin color. It is famous that consumer eats with their eyes and the major quality characteristic that create attraction towards the fruit is its color. Color scores of mangos in Figure 3(d) showed a tendency to increase at the beginning of storage and then declined at the end of the storage. The color score of mangos stored in ambient quickly fell after two days storage. However, the color score of mangos inside ZECC and refrigerator remained constant until 8 days of storage and gradually dropped until 11 days of storage. The main suspect was the loss of green color of mango, which was probably due to the physico-chemical changes by degradation of the chlorophyll and increased in carotenoid pigments during storage(Aina, 1990; Rathore, Masud, Sammi, \& Soomro, 2007). This result was consistent with a study done by Doreyappa \& Huddar (2001) who reported anincrease of the carotenoids concentration due to a series of physico-chemical changes in green mature mango stored at $18-34^{\circ} \mathrm{C}$ during ripening.

\subsection{General discussion}

The shelf-life and postharvest quality of mango fruits maintain better both in the refrigerator and zero energy cooling chamber with the addition of 20 liters of water per day by lowering the temperature and increasing relative humidity(Dirpan et al., 2017). The ZECC also give an alternative approach to mechanical refrigerator for prolonging postharvest shelf life and maintain quality of mangos. The ZECC is appropriate for retailers at market place, they can easily construct from locally available materials and extend the shelf life of their mango fruits as well as it protect from mechanical damage as they may face such problem in busy market place. In addition, experiment on different perishable produces on these storages should also be conducted to increase use of the storages.

In general, we found that the change in the quality parameters of mango dependent on postharvest treatments storage. Mango fruits inside ZECC slightly better than mangos stored in ambient and refrigerator in total titratable acidity, vitamin C, PLW and moisture content. On the other hand, mangos stored in refrigerator slightly exhibited better result in maintaining total soluble solids (TSS) rather than mangos inside ZECC and ambient condition. All sensorial analysis revealed that ZECC and refrigerator samples were superior rather than mango in ambient at the end of an eleven-day holding period. Interestingly, although the color of the mango that is stored in ZECC and refrigerator looks the same quality but there is a little mold on the mango stored in ZECC, this is probably due to the high relative humidity in ZECC than the refrigerator. Additionally, ZECC and refrigerator mango fruits exhibited slower decay and lower water loss. These results indicated that maintaining lower temperature and higher relative humidity during storage could maintain mango quality and would reduce physiological weight loss. Therefore, the study gave good indication that for a tropical country like Indonesia low cost, economically feasible technology such as on-farm lowcost storage of ZECC treatment seems to be appropriate. 


\section{Conclusion}

In this paper, we have presented the quality and storability of mango during zero energy cool chamber (ZECC) storage. Total titratable acidity, vitamin C, total soluble solids, physiological loss in weight (PLW), and moisture content of mangos inside ZECC ranged from 0.113 to $0.412 \%, 24.98$ to $78.97 \mathrm{mg} / 100 \mathrm{~g}, 11.1$ to $18.7{ }^{0}$ Brix, 0.0 to $6.2 \%$ and 73.6 to $94.7 \%$ respectively. In addition, all sensory evaluation showed that mangos inside ZECC were acceptable until eleven days of storage. Therefore, we concluded that the maintenance of quality and the extension of mango fruit shelf life by ZECC which presented here, reveals that such ZECC can be considered for commercial application during storage and marketing.

\section{Acknowledgment}

The authors gratefully thank the DP2M, Higher Education, Ministry of National Education, Republic of Indonesia for supporting this work via the National Strategic Research Program 2017 (Penelitian Strategi Nasional 2017).

\section{References}

Aina, J. O. (1990). Physico-chemical changes in African mango (Irvingia gabonensis) during normal storage ripening. Food Chemistry, 36(3), 205-212. https://doi.org/10.1016/0308-8146(90)90055-9

AOAC. (2005). Official methods of analysis of AOAC International. Association of Official Analytical Chemists International, II, Method ce 2-66. https://doi.org/10.3109/15563657608988149

Baldwin, E. A., Burns, J. K., Kazokas, W., Brecht, J. K., Hagenmaier, R. D., Bender, R. J., \& Pesis, E. (1999). Effect of two edible coatings with different permeability characteristics on mango (Mangifera indica L.) ripening during storage. Postharvest Biology and Technology, 17(3), 215-226. https://doi.org/10.1016/S09255214(99)00053-8

Baloch, M. K., Bibi, F., \& Jilani, M. S. (2013). Effect of coatings over the quality and shelf life of mango (mangifera indica 1.) fruit. Journal of Food Processing and Preservation, 37(1), 66-73. https://doi.org/10.1111/j.1745-4549.2011.00614.x

Chien, P. J., Sheu, F., \& Yang, F. H. (2007). Effects of edible chitosan coating on quality and shelf life of sliced mango fruit. Journal of Food Engineering, 78(1), 225-229. https://doi.org/10.1016/j.jfoodeng.2005.09.022

Dhumal, S., \& Karale, A. (2008). Response of Aonla Fruits Stored in Zero Energy Cool Chamber to Different Post Harvest Chemicals and Packagings. Annals of Horticulture, 1(1), 11-16.

Dirpan, A., Sapsal, M. T., Muhammad, A. K., Tahir, M. M., \& Rahimuddin. (2017). Evaluation of temperature and relative humidity on two types of zero energy cool chamber (ZECC) in South Sulawesi, Indonesia. IOP Conference Series: Earth and Environmental Science, 101, 012028. https://doi.org/10.1088/1755$1315 / 101 / 1 / 012028$

Doreyappa Gowda, I. N., \& Huddar, A. G. (2001). Studies on ripening changes in mango (Mangifera indica L.) fruits. Journal of Food Science and Technology, 38(2), 
135-137. Retrieved from http:/ / www.scopus.com/inward/record.url?eid=2-s2.00035267685\&partnerID=tZOtx3y1

Ganesan, M., Balasubramanian, K., \& Bhavani, R. . (2004). Studies on the application of different levels of water on Zero energy cool chamber with reference to the shelflife of brinjal. J. Indian Inst. Sci, 84, 107-111.

Hernandez, Y., Lobo, M. G., \& Gonzalez, M. (2006). Determination of vitamin C in tropical fruits: A comparative evaluation of methods. Food Chemistry, 96(4), 654664. https://doi.org/10.1016/j.foodchem.2005.04.012

Hoa, T. T., Ducamp, M.-N., Lebrun, M., \& Baldwin, E. A. (2002). Effect of Different Coating Treatments on The Quality Of Mango Fruit. Journal of Food Quality, 25(6), 471-486. https:// doi.org/10.1111/j.1745-4557.2002.tb01041.x

Islam, M. P., \& Morimoto, T. (2012). Zero energy cool chamber for extending the shelflife of tomato and eggplant. Japan Agricultural Research Quarterly, 46(3), 257-267. https://doi.org/10.6090/jarq.46.257

Islam, M. P., \& Morimoto, T. (2014). A new zero energy cool chamber with a solardriven adsorption refrigerator. Renewable Energy, 72, 367-376. https://doi.org/10.1016/j.renene.2014.07.038

Islam, M. P., \& Morimoto, T. (2015). Progress and development in brick wall cooler storage system. Renewable and Sustainable Energy Reviews, 50, 277-303. https:/ / doi.org/10.1016/j.rser.2015.05.019

Islam, M. P., Morimoto, T., \& Hatou, K. (2012). Storage behavior of tomato inside a zero energy cool chamber. Agricultural Engineering International: CIGR Journal, 14(4), 209-217.

Islam, M. P., Morimoto, T., \& Hatou, K. (2013). Dynamic optimization of inside temperature of Zero Energy Cool Chamber for storing fruits and vegetables using neural networks and genetic algorithms. Computers and Electronics in Agriculture, 95, 98-107. https://doi.org/10.1016/j.compag.2013.04.008

Jahurul, M. H. A., Zaidul, I. S. M., Ghafoor, K., Al-Juhaimi, F. Y., Nyam, K. L., Norulaini, N. A. N., ... Mohd Omar, A. K. (2015). Mango (Mangifera indica L.) byproducts and their valuable components: A review. Food Chemistry. https:// doi.org/10.1016/j.foodchem.2015.03.046

Jitareerat, P., Paumchai, S., Kanlayanarat, S., \& Sangchote, S. (2007). Effect of chitosan on ripening, enzymatic activity, and disease development in mango (Mangifera indica) fruit. New Zealand Journal of Crop and Horticultural Science, 35(2), 211-218. https://doi.org/10.1080/01140670709510187

Khader, S. E. S. A. (1990). Orchard application of paclobutrazol on ripening, quality and storage of mango fruits. Scientia Horticulturae, 41(4), 329-335. https:/ / doi.org/10.1016/0304-4238(90)90113-S

Lal Basediya, A., Samuel, D. V. K., \& Beera, V. (2013). Evaporative cooling system for storage of fruits and vegetables - A review. Journal of Food Science and Technology, 50(3), 429-442. https://doi.org/10.1007/s13197-011-0311-6

Malundo, T. M. M., Baldwin, E. a, Moshonas, M. G., Baker, R. a, \& Shewfelt, R. L. (1997). Method for the rapid headspace analysis of mango (Mangifera indica L) homogenate volatile constituents and factors affecting quantitative results. Journal of Agricultural and Food Chemistry, 45(6), 2187-2194.

Marques, E. J. N., De Freitas, S. T., Pimentel, M. F., \& Pasquini, C. (2016). Rapid and non-destructive determination of quality parameters in the "Tommy Atkins" mango using a novel handheld near infrared spectrometer. Food Chemistry, 197, 1207-1214. https://doi.org/10.1016/j.foodchem.2015.11.080 
Murugan, A., Ranjith, S. A. J. A., \& Vidhya, S. (2011). Evaluation of self-life and organoleptic aspects of fruits stored in a modified traditional earthen pot cool chamber. Indian Journal of Traditional Knowledge, 10(2), 375-379.

Narayana, C., Mustafa, M., \& Sathiamoorthy, S. (2002). Effect of packaging and storage on shelf-life and quality of banana cv. Karpuravalli. Journal of Dairying, Foods and Home Sciences, 59(2), 113-117.

No, H. K., Meyers, S. P., Prinyawiwatkul, W., \& Xu, Z. (2007). Applications of chitosan for improvement of quality and shelf life of foods: A review. Journal of Food Science. https:// doi.org/10.1111/j.1750-3841.2007.00383.x

Prabha, A., H.R, S., A.K, G., \& Ranjana, V. (2006). Changes in ascorbic acid content of lemon fruits stored in zero energy cool chamber and under ambient atmosphere. Journal of Dairying, Foods and Home Sciences, 25(1), 73-75.

Rathore, H. A., Masud, T., Sammi, S., \& Soomro, A. H. (2007). Effect of storage on physico-chemical composition and sensory properties of mango (Mangifera indica L.) variety dosehari. Pakistan Journal of Nutrition, 6(2), 143-148. https://doi.org/10.3923/pjn.2007.143.148

Rayaguru, K., Khan, M. K., \& Sahoo, N. R. (2010). Water use optimization in zero energy cool chambers for short term storage of fruits and vegetables in coastal area. Journal of Food Science and Technology, 47(4), 437-441. https://doi.org/10.1007/s13197-010-0072-7

Schmilovitch, Z., Mizrach, A., Hoffman, A., Egozi, H., \& Fuchs, Y. (2000). Determination of mango physiological indices by near-infrared spectrometry. Postharvest Biology and Technology, 19(3), 245-252. https://doi.org/10.1016/S09255214(00)00102-2

Sharma, R. R., Pal, R. K., Singh, D., Samuel, D. V. K., Kar, A., \& Asrey, R. (2010). Storage life and fruit quality of individually shrink-wrapped apples (Malus domestica) in zero energy cool chamber. Indian Journal of Agricultural Sciences, 80(4), 338-341.

Singh, S., Singh, a. K., Joshi, H. K., Bagle, B. G., \& More, T. A. (2010). Effect of zero energy cool chamber and post-harvest treatments on shelf-life of fruits under semi-arid environment of western India. Part 2. Indian gooseberry fruits. Journal of Food Science and Technology, 47(4), 450-453. https://doi.org/10.1007/s13197-0100075-4

Talcott, S. T., Moore, J. P., Lounds-Singleton, a J., \& Percival, S. S. (2005). Ripening associated phytochemical changes in mangos (Mangifera indica) following thermal quarantine and low-temperature storage. Journal of Food Science, 70(5), 337-341. https:// doi.org/10.1111/j.1365-2621.2005.tb09963.x

Tefera, A., Seyoum, T., \& Woldetsadik, K. (2008). Effects of disinfection, packaging and evaporatively cooled storage on sugar content of mango. Journal of Biotechnology, 7(1), 065-072.

Vala, K. V, Saiyed, F., \& Joshi, D. C. (2014). Evaporative Cooled Storage Structures : An Indian Scenario. Trends in Post Harvest Technology, 2(3), 22-32. 